\title{
AVALIAÇÃO DA QUALIDADE DO ÓLEO DE BURITI (MAURITIA FLEXUOSA L.) EM DIFERENTES CONDIÇÕES DE ESTOCAGEM VISANDO A SUA UTILIZAÇÃO EM BIOCOSMÉTICOS NATURAIS
}

\author{
C. S. ARAÚJO ${ }^{1 *}$, M. C. C. VALENTE ${ }^{1}$, E. B. SANTANA ${ }^{1}$, L. G. CORUMBÁ ${ }^{1}$, C. M. L. \\ $\operatorname{COSTA}^{1}$ \\ ${ }^{1}$ Universidade Federal do Pará, Faculdade de Engenharia Química \\ *E-mail para contato: camilasar.eng@gmail.com
}

RESUMO - O buriti (Mauritia flexuosa L.) é uma palmeira cujo fruto é rico em vitamina A, B, C, cálcio, ferro, proteínas e seu óleo têm quantidades significativas de carotenóides. É bastante promissor para as indústrias de cosméticos e alimentos, no entanto, a produção do óleo é baixa ou insuficiente para atender a demanda do mercado. Devido à falta de incentivo à sua utilização pela indústria em geral, busca-se através desta pesquisa estudar as propriedades de qualidade do óleo de buriti em diferentes ambientes. Na avaliação dos fatores degradativos do óleo, as amostras foram submetidas à câmara escura em temperatura ambiente, câmara com luz fluorescente $(15 \mathrm{~W})$, congelador e estufa $\left(50^{\circ} \mathrm{C}\right)$. Os parâmetros oleoquímicos analisados foram: índice de acidez, índice de saponificação e dienos conjugados. Através das análises experimentais foram verificados vários fatores influentes nas características do óleo de buriti, evidenciando o efeito destes fatores nas propriedades de qualidade deste.

\section{INTRODUÇÃO}

O buriti (Mauritia Flexuosa L.) é uma planta da família Arecaceae nativa da América Latina, principalmente no Brasil, Peru, Bolívia, Equador, Colômbia, Venezuela e Guiana. No Brasil ocorre nos seguintes Estados: AM, BA, DF, MG, GO, CE, MA, MS, MT, PA, PI, SP, TO (Henderson et al., 1995; Lorenzi et al., 2004).

Figura 1 - Frutos e óleo de buriti.

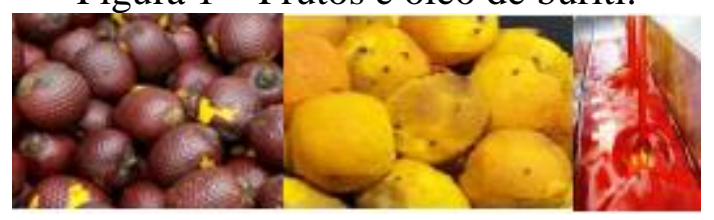

O óleo de buriti (Figura 1) é muito rico em ácido oléico (72,5\%), um tipo de ácido graxo monoinsaturado presente no azeite de oliva, que é associado a uma menor incidência de doenças coronarianas. Além disso, é considerado uma fonte natural rica em betacaroteno (30 $\mathrm{mg} / 100 \mathrm{~g}$ de polpa), superando a cenoura em 5 vezes $(6,6 \mathrm{mg} / 100 \mathrm{~g}$ de polpa). No óleo de buriti a concentração alcança 118 miligramas/100 g de óleo (Rodriguez-Amaya, 1996). O betacaroteno é um dos mais poderosos antioxidantes, conhecido por sua grande capacidade de renovação celular. Devido a sua capacidade de absorver radiações na faixa de luz visível e ultravioleta, o óleo de buriti se torna para a indústria cosmética um eficiente filtro solar que diminui o ressecamento da pele. 
Diversas reações podem ocorrer e produzirem numerosos compostos de degradação nos óleos, as quais alteram as propriedades funcionais, sensoriais e nutricionais. Os óleos, apesar da presença dos antioxidantes naturais, podem sofrer degradação natural devido a diversos fatores, tais como: presença de oxigênio, exposição à luz e variação de temperatura. Além destes, os processos de extração, de acondicionamento, adição de aditivos, condições ambientais e de transporte, se não forem adequadamente realizados, também podem influenciar na estabilidade dos óleos (Reda, 2007).

Devido a escassez de estudos que atestem as propriedades do óleo de buriti para a formulação de biocosméticos, busca-se através deste trabalho avaliá-lo em diferentes condições de estocagem, identificando parâmetros de qualidade que justifiquem e incentivem o apelo ao seu aproveitamento em formulações de biocosméticos naturais.

\section{MATERIAIS E MÉTODOS}

O óleo de buriti foi obtido comercialmente de produtores locais, no município de Bragança, Estado do Pará. O trabalho foi conduzido no laboratório de engenharia de produtos naturais (Lepron), FEQ/UFPa.

Os ambientes testados para verificação das alterações nas propriedades de qualidade do óleo do buriti foram: câmara escura, câmara com luz fluorescente (15W), congelador e estufa $\left(50^{\circ} \mathrm{C}\right)$. Os ensaios foram feitos em triplicata, por um período de 30 dias de análise.

A determinação do índice de acidez (I.A.) foi calculada pela Equação 1, onde 2,0 g de cada amostra foram dissolvidas com $25 \mathrm{~mL}$ de solução neutra de éter-álcool, sendo adicionadas duas gotas do indicador fenolftaleína $1 \%$, com posterior titulação da mistura com a solução de hidróxido de sódio $0,1 \mathrm{~N}$, até o aparecimento da cor rósea persistente por 30 segundos (AOCS-1986). Sendo: $f_{1}$ - fator de correção da solução de hidróxido de sódio $0,1 \mathrm{~N}$; $\mathrm{P}$ - número de gramas da amostra e $V_{1}$ - volume de $\mathrm{mL}$ de hidróxido de sólido $0,1 \mathrm{~N}$ gasto na titulação.

$$
\text { I. A. }(\mathrm{mg} \mathrm{KOH} / g)=\frac{V_{1} \times f_{1} \times 5,61}{\mathrm{p}}
$$

O índice de saponificação (I.S.) do óleo de buriti foi determinado submetendo-se 4,0 g da amostra, adicionada de $50 \mathrm{~mL}$ da solução alcoólica de $\mathrm{KOH}$ a $4 \%$ (p/p), ao aquecimento com refluxo, obtido pelo acoplamento do balão de fundo chato contendo a amostra, a um condensador. Deixou-se ferver suavemente até a completa saponificação da amostra (aproximadamente 1 hora). Após o resfriamento do balão, adicionou-se $1 \mathrm{~mL}$ de solução do indicador fenolftaleína, titulando-se com solução de ácido clorídrico $0,5 \mathrm{~N}$ até $\mathrm{o}$ desaparecimento da cor rósea. $\mathrm{O}$ mesmo procedimento foi utilizado com o branco. $\mathrm{O}$ índice de saponificação do óleo foi calculado a partir da Equação 2 (AOCS Cd 3-25), onde: $f_{2}$ - fator do ácido clorídrico $0,5 \mathrm{~N}$; $\mathrm{m}$ - massa da amostra em gramas e $V_{2}$ - diferença entre os números de $\mathrm{mL}$ do ácido clorídrico $0,5 \mathrm{~N}$ gastos nas duas titulações.

$$
\text { I. S. }(\mathrm{mg} \mathrm{KOH} / g)=\frac{V_{2} \times f_{2} \times 28}{m}
$$

Os teores de dienos conjugados (DC) dos óleos obtidos a partir do fruto de buriti foram expressos em porcentagem de ácidos dienóicos conjugados. As amostras de óleo foram 
diluídas em iso-octano (2,2,4-trimetilpentano), utilizando-se balões de $10 \mathrm{~mL}$. As absorbâncias foram medidas em espectrofotômetro a $233 \mathrm{~nm}$. Os teores de dienos conjugados foram calculados através da Equação 3 (AOCS Ti la-64, 1993) e as médias dos resultados dos diferentes métodos de estocagem foram analisadas através das médias significativas (Tukey) a 95\%. Sendo: A - absorbância; b - espessura da cubeta, em cm; c - concentração da amostra, em $\mathrm{g} / \mathrm{L}$ e $\mathrm{K}_{0}$ - absortividade para grupos ácidos $(0,03)$ ou ésteres $(0,07)$.

$$
D C(\%)=0,84\left(\frac{A}{b \times c}-K_{0}\right)
$$

\section{RESULTADOS E DISCUSSÃO}

\subsection{Análise in natura do óleo}

O óleo de buriti in natura foi analisado segundo as suas propriedades físico-químicas e os resultados obtidos estão dispostos na Tabela 1.

Tabela 1 - Propriedades do óleo de buriti.

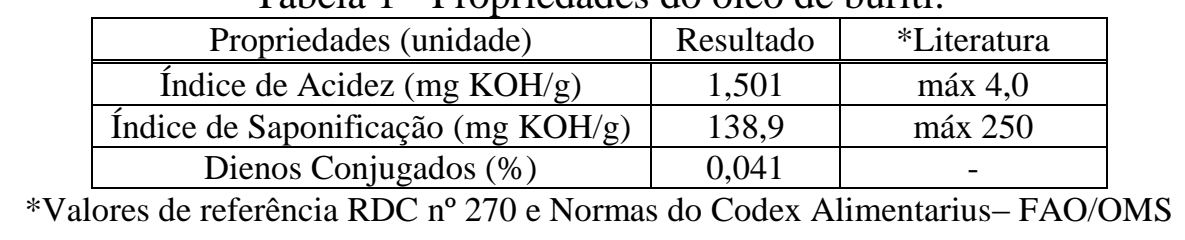

As análises oleoquímicas demonstram-se similares aos encontrados na literatura. Verifica-se, com base na Tabela 1, que os valores obtidos para a composição de índices de acidez, saponificação e dienos conjugados, apresentam-se dentro dos limites estabelecidos pelas legislações vigentes. Sendo assim, o óleo de buriti analisado se enquadrou nos limites propostos pela legislação para óleos não refinados.

\subsection{Análise da Qualidade do Óleo de Buriti após as Diferentes Condições de Estocagem}

A Figura 2 mostra os resultados da qualidade do óleo de buriti através do seu índice de acidez em cada ambiente estudado. Constata-se um aumento gradual do índice de acidez nos trinta dias de análise, das amostras analisadas na câmara escura, câmara com luz fluorescente e estufa.

O índice de acidez é um bom parâmetro para avaliar a qualidade de óleos, já que a maior parte dos constituintes dos óleos é oxidável em diferentes graus e ambientes, sendo que os ácidos graxos insaturados são as estruturas químicas mais suscetíveis ao processo oxidativo, o que explica o aumento da acidez do óleo de buriti nos três ambientes testados. Um elevado índice de acidez indica, também, que o óleo ou gordura está sofrendo quebras em sua cadeia de trigliceróis, liberando seus constituintes principais: os ácidos graxos (Alves et $a l .$, 2009). Este é um indicativo de primeiro estágio de decomposição do óleo, sendo que quando ultrapassa o valor limite, começam a surgir espécies reativas de oxigênio, principalmente peróxidos, substâncias potencialmente tóxicas (Bobbio et al., 2001). Já nas amostras analisadas no congelador, o índice de acidez do óleo de buriti não apresentou nenhuma alteração significativa. 
Figura 2 - Resultado das análises de índice de acidez do óleo de buriti.

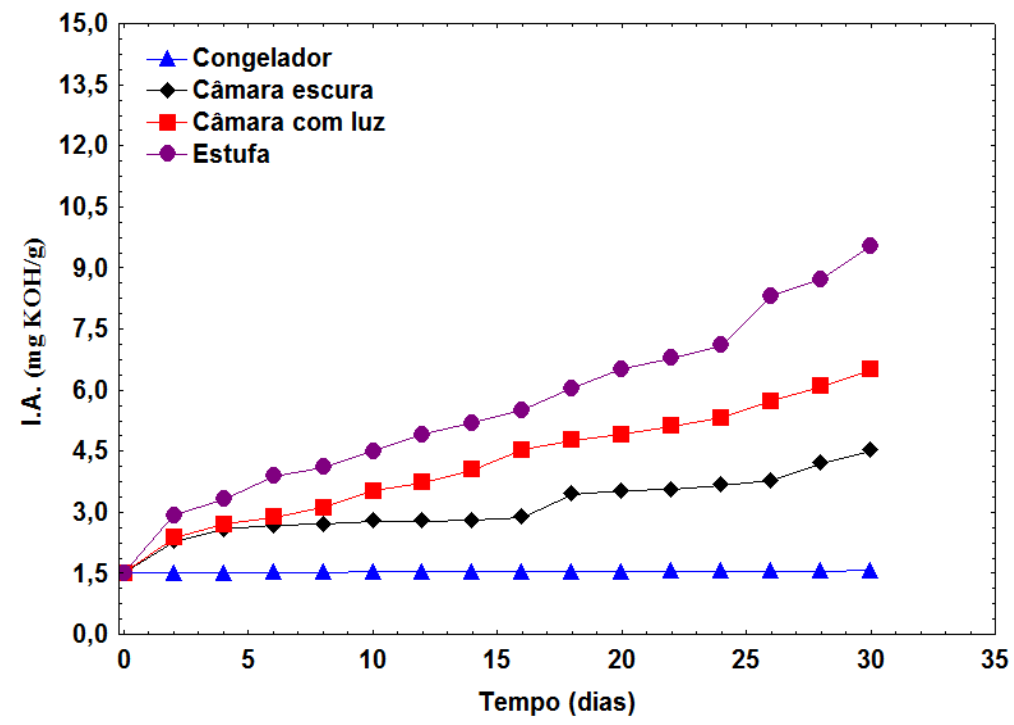

Conforme mostra a Figura 3, observa-se com o tempo de exposição às condições estudadas, que o índice de saponificação aumentou para o óleo de buriti, nas amostras analisadas na câmara escura, câmara com luz fluorescente e estufa. Já as amostras analisadas no congelador apresentaram uma pequena variação, mas esses valores não ultrapassaram o valor máximo recomendado pela literatura que é de $250 \mathrm{mg} \mathrm{KOH/g}$.

Figura 3 - Resultado das análises de índice de saponificação do óleo de buriti.

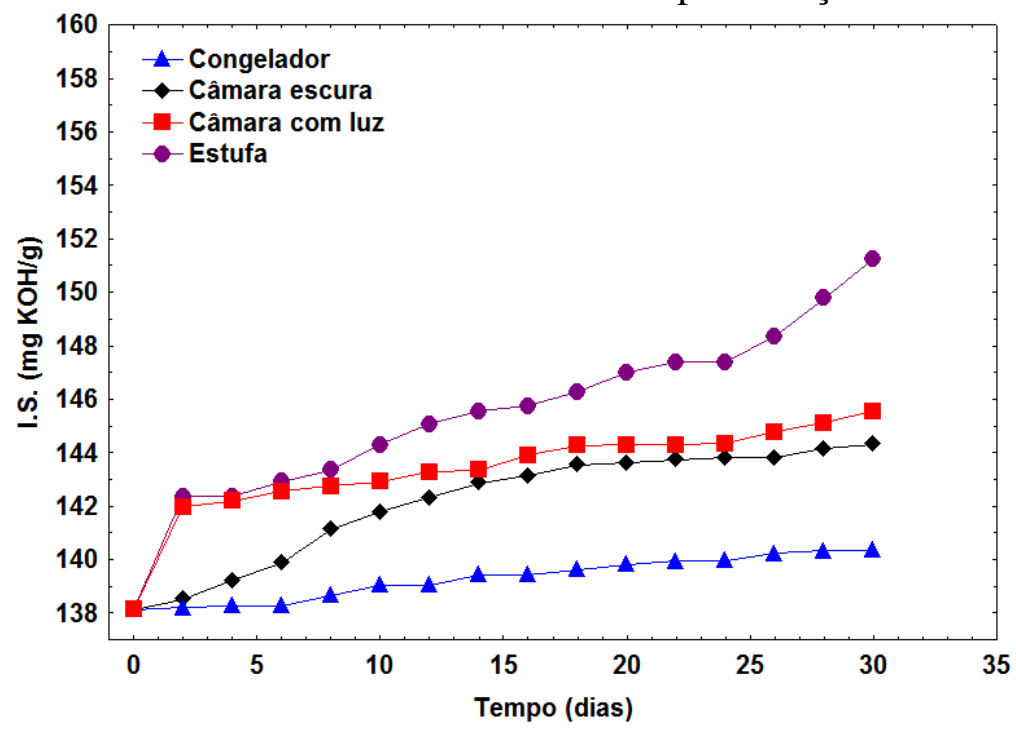

Os resultados observados na Figura 3 mostram que as diferentes condições de estocagem analisadas propiciam a quebra das cadeias de trigliceróis, liberando os triglicerídeos, ácidos graxos de baixo peso molecular. Sendo assim, mais agente titulante é gasto, aumentando o índice de saponificação das amostras analisadas. Além disso, a elevação na concentração dos ácidos graxos demonstra que o óleo de buriti não se encontra estável durante o período analisado. A estabilidade térmica dos óleos depende de sua estrutura química, sendo os óleos com ácidos graxos insaturados menos estáveis do que os saturados, como observado por Aroucha et al (2010). 
Observa-se na Tabela 2, em relação aos tempos de análise, que as alterações de dienos conjugados foram crescentes nas amostras analisadas na câmara escura, câmara com luz fluorescente e estufa. É importante ressaltar que em relação às demais amostras, as amostras da estufa foram as que obtiveram maior aumento, considerando assim, o aumento da temperatura como influência direta no aumento dos compostos primários de oxidação destas.

Tabela 2 - Resultado das análises de dienos conjugados do óleo de buriti.

\begin{tabular}{|c|c|c|c|c|c|}
\hline \multicolumn{7}{|c|}{ Dienos conjugados (\%) } \\
\hline Meio & $1^{\circ}$ dia & $7^{\circ}$ dia & $14^{\circ}$ dia & $21^{\circ}$ dia & $30^{\circ}$ dia \\
\hline Câmara escura & 0,042 & 0,043 & 0,043 & 0,043 & 0,043 \\
\hline Câmara com luz & 0,042 & 0,043 & 0,043 & 0,043 & 0,043 \\
\hline Congelador & 0,042 & 0,041 & 0,041 & 0,041 & 0,041 \\
\hline Estufa & 0,042 & 0,049 & 0,049 & 0,050 & 0,050 \\
\hline
\end{tabular}

$\mathrm{Na}$ Tabela 3 são apresentados os resultados do teste de comparação das médias significativas (Tukey), que demonstrou a formação de dois grupos distintos para o teor de dienos conjugados do óleo de buriti. Pelos quais, se observa que as amostras analisadas na estufa são diferentes estatisticamente das demais, além de apresentarem o teor de dienos superior. Sendo que, o teor de dienos da câmara escura, da câmara com luz e do congelador se mostraram estatisticamente iguais.

Tabela 3 - Dienos conjugados do óleo de buriti nas diferentes condições de estocagem.

\begin{tabular}{|c|c|}
\hline Meio & Dienos conjugados (\%) \\
\hline Câmara escura & $0,041 \mathrm{a}$ \\
\hline Câmara com luz & $0,043 \mathrm{a}$ \\
\hline Congelador & $0,043 \mathrm{a}$ \\
\hline Estufa & $0,048 \mathrm{~b}$ \\
\hline
\end{tabular}

*Médias seguidas de mesma letra não diferem entre si

As alterações ocorridas nos dienos conjugados para o óleo de buriti armazenado em estufa a $50^{\circ} \mathrm{C}$ por 30 dias podem ser explicadas devido provavelmente a oxidação de ácidos graxos poliinsaturados representado pelo aumento da absortividade na faixa do espectro ultravioleta. Durante a oxidação, lipídios contendo dienos ou polienos apresentam uma alteração na posição de suas duplas ligações, resultado da isomerização e conjugação. A formação de dienos e trienos é proporcional ao ganho de oxigênio e à formação de peróxidos durante os estágios iniciais de oxidação (Lugasi et al., 1995). Segundo Faria e EspinozaAtencia (1994), a medida da percentagem de ácidos dienóicos conjugados é um método alternativo para monitorar estudos sobre a oxidação de óleos.

\section{CONCLUSÃO}

Constatou-se um aumento gradual do índice de acidez nos trinta dias de análise, das amostras analisadas na câmara escura, câmara com luz fluorescente e estufa. Já as amostras analisadas no congelador não apresentaram aumento significativo. As alterações nos valores obtidos não ficaram fora dos padrões exigidos pela legislação, no entanto, os resultados indicam que, ao se acentuar o tempo de exposição do óleo à luz e à alta temperatura, com o decorrer do tempo existe tendência de que os valores continuem mudando, podendo comprometer significativamente a qualidade do óleo de buriti. 
Já os valores obtidos para o índice de saponificação tiveram um aumento para esse índice, mas esses valores não ultrapassaram o valor máximo recomendado pela literatura que é de $250 \mathrm{mg} \mathrm{KOH} / \mathrm{g}$.

O teor de dienos conjugados apresentou ligeiras modificações em seus valores, se comparados aos valores obtidos nos ensaios iniciais. A temperatura de armazenamento apresentou relação direta com o aumento dos compostos primários de oxidação das amostras de óleo de buriti analisadas.

\section{REFERÊNCIAS}

ALVES, R. F.; GUIMARÃES, S. M.; ABREU T. C.; SILVA, R. D. Índices de Acidez Livre e de Peróxido. Relatório para a Disciplina de Bioquímica, Curso Técnico de Química Industrial, Centro de Educação Profissional Hélio Augusto de Sousa, São José dos Campos, SP, 2009.

AMERICAN OIL CHEMISTS' SOCIETY. Official methods and recommended practices of the American Oil Chemists' Society. 4th ed. Champaign, USA. A.O.C.S., 1990. [A.O.C.S. Official method Cd 3-25].

AOCS (American Oil Chemists' Society) Official methods and recommended practices of the American Oil Chemists' Society. Champaign: AOCS, 1993.

AROUCHA, I.; RANGEL, J. H. G.; OLIVEIRA, M. M; MOURA, A. Estudo da estabilidade oxidativa dos óleos de buriti e babaçu, 2010. Disponível em: $<$ http://congressos.ifal.edu.br/index.php/connepi/CONNEPI2010/paper/viewFile/945/69 9>. Acesso em: 05 de maio de 2017.

BOBBIO, P.A.; BOBBIO, F.O. Química do processamento de alimentos, 3.ed. São Paulo. 33p, 2001.

CODEX ALIMENTARIUS. Norma del codex para aceites vegetales especificados.Codex stan 210, 2005. In: FAO - Food and Agriculture Organization of the United Nations. Disponível em: <http://codexalimentarius.net/download/standards/336/CXS_210s.pdf>. Acesso em: 25 de fevereiro de 2016.

FARIA, J. A. F.; ESPINOZA ATENCIA, E. J. Fotoxidação de óleos comestíveis em embalagens plásticas transparentes. Óleos e Grãos, vol. 19, pg. 44-51, 1994.

HENDERSON, A.; GALEANO, G. \& BERNAL, R. Field Guide to the Palms of the Americas. New Jersey, Princeton University Press. 1995.

LORENZI, H.; SOUZA, H. M. de; CERQUEIRA, L. S. C.; MEDEIROS-COSTA, J.T.; FERREIRA, E. Palmeiras brasileiras e exóticas cultivadas. Nova Odessa, SP: Instituto Plantarum, 2004. 416 p. il.

LUGASI, A. HÓVARI, J.DWORS CHAK, E. Effect of UV irradiation on lipid peroxidation edile fats. Acta Alimentaria. v. 24, n.3, p. 269-276, 1995.

REDA, S. Y.; CARNEIRO, P. I. B. C. Óleos e gorduras: Aplicações e implicações. Revista Analytica. n. 27, p. 60-67, 2007.

RODRIGUEZ-AMAYA, D. B. (1996) Assessment of the provitamin A contents of foods the Brazilian experience. Journal of Food Composition and Analysis, v. 9, p.196-230. 